\title{
Het beroep op de proef
}

Mr. P.J.M. von Schmidt auf Altenstadt

\section{Maatschappelijke taak en functie}

Een aantal maatschappelijke taken en functies worden zo belangrijk gevonden dat zij worden opgedragen en voorbehouden aan in die taak en functie gespecialiseerde beroepen. Denk maar aan de gezondheidszorg, de rechtshulp en de controle van jaarstukken. Voor al deze professionals is een wettelijke regeling in het leven geroepen. Ik doel dan op de beroepen in de individuele gezondheidszorg (de wet BIG 1993), de Advocatenwet van 1952, de Wet op het Notarisambt van 1842 , ingrijpend gewijzigd in 1999, en de Wetten op de Registeraccountants van 1962 en op de Accountants-Administratieconsultanten van 1972 , beide gewijzigd in 1993. Al deze wetten kennen een stelsel van registratie, beroepstitelbescherming, opleidingseisen, een stelsel van tuchtrechtspraak en strafbepalingen tegen hen die onbevoegd het beroep uitoefenen. Behalve in de gezondheidszorg is gekozen voor publiekrechtelijke beroepsorganisaties waaraan in hoge mate de zelfregulering van het beroep is overgelaten. Natuurlijk binnen de kaders van een goede praktijk en beroepsuitoefening. De taak en functie van de personen belast met de wettelijke controle van boekhoudbescheiden werd zelfs op Europees niveau zó belangrijk gevonden dat in de achtste Richtlijn inzake het vennootschapsrecht van 10 april 1984 (nr. 84/ 253 /EEG) de lidstaten is opgedragen voor deze professionals voorschriften in het leven te roepen met betrekking tot de toelating tot het verrichten van controlewerkzaamheden. De Raad van de EG benadrukte het belang van beroepsethiek en onafhankelijkheid voor het beroep van accountant.

Mr. P.J.M. von Schmidt auf Altenstadt studeerde Nederlands recht aan de Rijksuniversiteit Leiden. Sinds 1975 is hij als advocaat verbonden aan de maatschap Houthoff Buruma. Tot 2 december 2000 was hij Deken van de Nederlandse Orde van Advocaten.
Kortom, de wet heeft de bijzondere positie en specifieke rol van een aantal professionals wettelijk erkend. En er is hun zelfs een monopolie toegekend. Alléén de arts mag de geneeskunst uitoefenen en ook de bevoegdheid van een zevental andere gezondheidsberoepen - van tandartsen tot verpleegkundigen - is minutieus geregeld.

En alléén de advocaat mag voor de burgerlijke en strafrechter een procespartij vertegenwoordigen (art. 133, 353, 407 lid 3 jo. 409, 429d lid 3 Rv., $37 \mathrm{~Sv}$.). En alléén de notaris mag akten verlijden die te maken hebben met de eigendom van onroerend goed (art. 3:31 BW), testamenten (art. 4:984 BW), huwelijksvoorwaarden (art. 1:115 BW), het oprichten van stichtingen en vennootschappen (art. 2:54, $64 \mathrm{lid} 2,175 \mathrm{lid} 2$, $286 \mathrm{BW}$ ) en de overdracht van aandelen (art. 2:86 BW). En zo is alleen de accountant bevoegd om de wettelijke controle van de jaarrekening uit te voeren (art. 2:393 BW). Deze 'monopolies' zijn alleen gerechtvaardigd zolang de kwaliteit van de beroepsuitoefening gewaarborgd is, niet alleen in vaktechnisch verband maar ook in beroepsethisch opzicht.

\section{Kennis en kunde}

Kennis en kunde is van het grootste belang voor een goede beroepsuitoefening. De patiënt, de cliënt en de samenleving moeten kunnen rekenen op verantwoorde zorg van daartoe bij uitstek - immers wettelijk - aangewezen personen. Aan het ontwikkelen en op peil houden van een vakbekwaamheid die aan de eisen van de maatschappij beantwoordt, besteden de beroepsorganisaties veel tijd en geld. Tot een systematische bewaking, beheersing en verbetering van de kwaliteit van de medische, rechtskundige en controlerende zorg behoort onverbrekelijk een systeem van intervisie of intercollegiale toetsing. Zo kent het NIVRA een verordening op de Collegiale Toetsing van 12 december 1996. Wat dat betreft loopt de 
advocatuur achter. Dat is niet onbegrijpelijk want eigenlijk alleen het beroep van advocaat is 'partijdig'. Gegevens die op de cliënt en zijn zaak betrekking hebben mogen niet terechtkomen bij de advocaat van de tegenpartij. Dat betekent dat aan een systeem van intervisie binnen de balie hoge eisen moeten worden gesteld waar het de cliëntgegevens betreft. Maar zo'n systeem moet er wel komen!

En inderdaad is de functie die de verschillende beroepen in de maatschappij vervullen niet dezelfde. Zo behoren de artsen, advocaten en notarissen tot de vertrouwenspersonen. $Z \mathrm{Zij}$ hebben een beroepsgeheim dat in het strafrecht (art. $218 \mathrm{~Sv}$.) en het civiele recht (art. $191 \mathrm{Rv}$.) is erkend met een verschoningsrecht ${ }^{1}$. Het zijn personen tot wier taak het behoort aan anderen hulp te verlenen; zij kunnen die taak alleen dan naar behoren vervullen indien zij zich ook tegenover de (straf)rechter kunnen verschonen ten aanzien van geheimen die aan hen zijn toevertrouwd door hulpzoekenden. Indien niet de zekerheid zou bestaan dat zulke geheimen ook tegenover de (straf)rechter worden bewaard, zouden hulpzoekenden - in strijd met het algemeen belang - geen hulp vragen aan de arts, de advocaat of notaris. De functies van de accountant zijn primair controlerend. Belanghebbenden bij de goede vervulling van die controlerende functie zijn in het bijzonder drie categorieën. In de eerste plaats groepen die door middel van de kapitaal en geldmarkt belanghebbenden zijn, zoals aandeelhouders, obligatie en pandbriefhouders, polishouders, pensioentrekkers, banken, spaarders enzovoort. Voorts de overheid, en ten slotte bestuurders van ondernemingen, instellingen en diensten van allerlei aard waarbij ook kan worden gedacht aan de werknemers en in het bijzonder de ondernemingsraad. De verscheidenheid in belangen van deze categorieën brengt met zich mee dat hetgeen de accountant bekend wordt in het kader van zijn controle niet kan worden ontbeerd bij het aan de dag brengen van de waarheid ${ }^{2}$. De NIVRAVerordening op de fraudemelding van 21 juni 1994 is hiervan een uitdrukking.

\section{Marktontwikkelingen}

De bijzondere beroepen hebben zich in een snel veranderende maatschappij ontwikkeld in de richting van professionele zakelijke dienstverleners. De inmiddels sterk narcistische samenleving op zoek naar steeds grotere welstand heeft weinig boodschap aan het eerzame beroep van arts, advocaat of notaris of accountant. Notabelen zijn het allang niet meer in de ogen van hun omgeving. En zij hebben zich razendsnel aangepast aan de veranderingen van de tijd, en vooral van de snel internationaler wordende zakenwereld. Gewoon uit nuchter eigenbelang, want wie niet meeloopt of liever gezegd het tempo niet bijhoudt, wordt ingehaald door andere dienstverleners. En dan heeft hij niet alleen zijn status maar ook zijn markt verloren. Het zijn allemaal relatief eenvoudige economische wetmatigheden. En voor hen die de markt tot meester verheffen is dat ook niet vreemd. Ik illustreer dat aan de ontwikkelingen binnen de advocatuur.

Het 'ambacht' werd nog in de jaren twintig door een gering aantal beroepsgenoten verricht dat maar langzaam groeide; van 877 in 1920 tot 1507 in 1947. In dat jaar liet de balie het belastingrecht schieten omdat het niet 'nobile' genoeg was. Tot 1960 praktiseerden deze advocaten nog alleen of in maatschapsverband met twee of drie anderen; soms waren bij de praktijkvoering jongeren betrokken, als volontair. Het maken van reclame was ongeoorloofd, cliënten mochten alleen op kantoor worden ontvangen, en onvermogenden werden 'pro deo' terzijde gestaan. Dan treedt een stormachtige ontwikkeling in, met drie fusiegolven rond 1968, eind jaren zeventig en eind jaren tachtig. Die concentratiebewegingen hielden verband met schaalvergroting in de bankwereld in het verzekeringswezen en in het (internationale) bedrijfsleven, en de vraag naar specifieke expertise. Advocatenkantoren haalden notarissen in huis en trachtten het aan de accountants verloren belastingrecht terug te veroveren. Megakantoren waren het gevolg, met meer dan 200 fee-earners, met vestigingen in het buitenland en vaak deel uitmakend van een internationale, vaak door Engelsen gedomineerde samenwerking. Een organisatie ook die meer lijkt op een vennootschap dan op een traditionele maatschap. En ook de inhoud, de aard van het werk, is gaandeweg veranderd en in elk geval gediversifieerd. De klemtoon is gaan liggen op het autonome advieswerk, los van enig (dreigend en te voorkomen) proces. Contracten schrijven, fusies, overnames, beursgangen, financiële producten ontwikkelen en 'vermarkten'. Gefinancierde rechtsbijstand aan minder draagkrachtigen hoort daar niet bij. Ook omdat de materiedeskundigheid op gebieden als familierecht, commuun strafrecht, vreemdelingenrecht en sociaal verzekeringsrecht niet (meer) voorhanden is, én omdat die domweg te weinig opbrengt. Want de kostenratio verbonden aan het in stand houden en uitbreiden van een groot kantoor is zeer aanzienlijk. Natuurlijk heb ik het nu vooral over de advocatenkantoren die zich richten op de vaak gespecialiseerde zakelijke dienstverlening. Dat veronderstelt een zakenwereld die het advies en transactiewerk nodig heeft en die bereid is daarvoor een hoge prijs te betalen. In de booming economie van vandaag wordt ruimschoots aan 
deze bestaansvoorwaarden voor het moderne advocatenkantoor voldaan. In een krimpende arbeidsmarkt wordt gevochten om het juridisch talent: headhunting, dat vroeger beneden de waardigheid van advocaten was, wordt zonder gêne toegepast, soms gecamoufleerd maar vaak onverholen. Evenals aanbrengpremies of welkomstbonussen (golden hellos). Ook deze ontwikkeling bevordert weer de doorgroci van een steeds commerciëler wordende advocatuur. Jongeren zoeken de beste arbeidsvoorwaarden en de sterkste perspectieven, qua loopbaan en qua inkomen. De idealist wordt een 'dief van zijn eigen portemonnee'; daarom ook verleggen sociale advocaten hun aandachtsgebied van gefinancierde rechtshulp naar de betalende praktijk. Een droevige ontwikkeling omdat die rechtzockenden die geen deel uitmaken van de wereld van Peter Stuyvesant achteraan in de rij terechtkomen. Zij worden nog bediend door die advocaten die de zakenwereld niet tot hun klant kunnen of willen rekenen. Van de tegenwoordig meer dan tienduizend advocaten is dat een slinkend aantal, vrees ik. Maar de spelregels die eigen zijn aan de marktwerking dicteren onverbiddelijk de richting. Bij een toenemende vraag stijgt de prijs en wordt de dienstverlening verlegd naar het meest lucratieve marktsegment. Een samenleving die de marktwerking tot kampioen uitroept en daartoe hartelijk wordt aangemocdigd door de overheid, moet niet alleen de zegeningen daarvan tellen maar ook de nadelige effecten voor lief nemen. Verstevigden de advocaten hun positie in de markt nog alleen door de rechtspraktijkformule uit te bouwen, met notarissen en met belastingadviseurs, de accountants pakten de wereld met grootser plannen aan. De firma's - en dan vooral de Big Five - diversifieerden onbekommerd zonder zich aan de controleformule te houden. Zij haalden de meest uiteenlopende, soms prestigieuze adviesdiensten in huis. Hun eerste verovering was de belastingadviespraktijk, zelfs zo ingrijpend dat er al gauw nauwelijks meer zelfstandige belastingadvieskantoren overbleven. Al spoedig werden ook brede consultancydiensten ingelijfd, van IT tot HR. En ten slotte werd ook het juridisch advies in het pakket gestopt. Onder het motto dat de markt deze ontwikkeling wil. Of dat het sterkste motief was, waag ik te betwijfelen. De legitieme economische prikkel om aantrekkelijk rendement te tonen zal niet vreemd zijn geweest aan deze supermarktgedachte. Al was het maar omdat de controlewerkzaamheden door de concurrentie en door de automatisering niet (meer) lucratief zijn. Deze uitbundige concentratie van controlewerkzaamheden pur sang met adviesdiensten verdraagt zich niet met de Achtste Richtlijn die in art. 2 lid 1 voorschrijft dat stemrecht en bestuur in meerderheid in handen van de accountants moeten liggen ${ }^{3}$. Deze 'spanning' wordt opgeheven door te benadrukken dat, behalve in Duitsland, alleen natuurlijke personen en niet (ook) vennootschappen worden toegelaten om de wettelijke controle te verrichten. Deze interpretatie van de Richtlijn lijkt onjuist. De slotzin van art. 2:393 BW laat toe dat de opdracht tot onderzoek van de jaarrekening wordt opgedragen aan "een organisatie waarin accountants die mogen worden aangewezen samenwerken'. Het woord 'organisatie' omvat allerlei samenwerkingsvormen, zoals de maatschap, de vennootschap of rechtspersoon. En in het maatschappelijk verkeer is het een accountantsorganisatie die naar buiten treedt. zelfs in die mate dat de accountantsverklaring is ondertekend met de naam van de organisatie. Desalniettemin gaan art. 58 Wet RA en 38 Wet $\mathrm{AA}$ ervan uit dat alleen natuurlijke personen in het accountantsregister worden ingeschreven. Dat lijkt in strijd met art. 28 van de achtste Richtlijn en met een behoorlijke bescherming van het maatschappelijk verkeer ${ }^{4}$.

De contaminatie van controle en verslaglegging met tal van adviesdiensten heeft inmiddels ook de aandacht van de Amerikaanse toezichthouder SEC getrokken. Deze beurswaakhond heeft een lijst van diensten samengesteld die 'inconsistent zijn met de onafhankelijkheid van accountants'. Het gaat dan om diensten zoals bedrijfswaarderingen, fusie- en overnamebemiddeling, advies op het gebied van human resources en juridische diensten. Veel accountantsconcerns zijn bezig met ingrijpende herstructureringen waardoor de verschillende activiteiten verzelfstandigd, of zelfs verkocht worden om de weg vrij te maken voor een beursgang. Tot voor kort wilde de markt nog de one stop shopping-formule, nu vallen concerns uiteen omdat een machtig toezichthoudend lichaam dreigende taal spreekt. En dan bedoel ik niet het toezichthoudend orgaan van de accountants zelf, maar van de beursgenoteerde bedrijven in de Verenigde Staten. Intussen is de splitsing tussen controle en advies, die inmiddels ook hoger op de politieke agenda in Nederland staat, een gelukkige. Je kunt het advieswerk van je eigen mensen nu eenmaal niet onafhankelijk certificeren; dan ben je niet meer geloofwaardig, bij de klant niet en bij de maatschappij niet. Accountants verkopen toch zekerheid?

Heel anders is het gelopen in de gezondheidszorg. Die markt wordt vrijwel geheel gedirigeerd door de overheid. Van marktwerking is niet of nauwelijks sprake want de overheid bepaalt tempo en richting. Het merendeel van de artsen en andere in de zorg werkenden is bij ziekenhuizen 
en dergelijke in loondienst of iets wat daar op lijkt. En het zal niet lang meer duren of zorgverzekeraars gaan er eigen ziekenhuizen op nahouden. Waarmee een gevaarlijke ontwikkeling wordt ingezet: een vermenging van belangen die niet parallel (hoeven te) lopen. Beslissingen in de gezondheidszorg behoren niet te worden gedicteerd door rendementsoverwegingen. Maar intussen leidt het dirigisme in de markt voor gezondheidszorg evenmin tot een soepele verwerking van vraag en aanbod. De wachtlijsten zijn een voortdurende ergernis, de aantrekkelijkheid van het beroep van arts of bijvoorbeeld verpleegster neemt af. Deze sector heeft met hele andere dilemma's te maken dan die welke advocaten en accountants ontmoeten. In de meeste gevallen ontbreekt de directe verleiding van het grote geld. Zij worden juist geconfronteerd met de schaarste aan middelen en mensen. Dat dwingt straks in een snel vergrijzende samenleving tot bijna onmenselijke keuzes. In een context van regels en regeltjes en zonder de bewegingsvrijheid die andere vrije beroepen (nog) hebben. Zij zijn 'beheerders' geworden, van het bedrijf van een ander.

\section{Het beroep op de proef}

Advocaten en notarissen hebben een indrukwekkend aanpassingsvermogen getoond. In de markt voor rechtskundige dienstverlening (in 1996: 5,3 miljard; omzet gerealiseerd door bedrijfsjuristen en juristen in dienst van accountantskantoren niet meegeteld) nemen advocatuur en notariaat samen voor $72 \%$ deel. Hun omzet steeg van 1990 tot en met 1996 met zo"n 50\%. Het aantal ondernemingen stijgt en dat is ook het geval met het aantal werkzame personen. De rechtsgebieden waaraan advocaten hun tijd besteden blijken afhankelijk van de omvang van het kantoor. Naarmate het kantoor groter wordt, wordt meer tijd besteed aan de ondernemingsrechtpraktijk, aan contractenwerk en aan vastgoed en bestuursrecht. Kleinere kantoren daarentegen besteden meer tijd aan personen-, familie- en erfrecht, arbeids- en sociaalzekerheidsrecht, straf- en strafprocesrecht en aan vreemdelingenrecht. De professionalisering binnen het advocatenberoep komt tot uitdrukking in een toenemend bedrijfsmatige aanpak in een steeds zakelijker omgeving. Targets worden ontwikkeld, businessplannen vastgesteld, rendementsoverwegingen geven de doorslag. Dat gaat weer gepaard met het dicteren van een strategie, van leverage en billable hours. De vrije beroeper wordt geperst in het keurslijf van een organisatie van professionals. Daarmee verandert langzaam ook het type advocaat. Nederlandse advocaten zijn van nature geen kuddedieren, het zijn individualisten bij uitstek. Hun allergie voor hiërarchische verhoudingen is bijna spreekwoordelijk. Zij claimen vrijheid en onafhankelijkheid voor van alles en nog wat; voor de eigen werkomgeving en voor de manier waarop zij de praktijk uitoefenen. Zij kiezen voor de beperkingen van een veeleisende praktijk met ongeduldige cliënten maar zij verzetten zich tegen strakke kaders die samen met een door anderen geplande toekomststrategie 'van boven' wordt opgelegd. Een nadrukkelijke organisatiestructuur die aangeeft wat deze advocaat wel en niet mag doen gaat onherroepelijk ten laste van de creativiteit en de innovatieve instelling, de inzet ook en de productie. Maar vloeit deze 'grondhouding' niet onvermijdelijk voort uit de aard van de traditionele werkzaamheden van de advocaat? Het oplossen van, vaak ingewikkelde, juridische problemen, de zaaksgewijze competitie en het voorkomen van en optreden in complexe conflicten vereist een houding die aandacht vraagt voor het detail, een houding die steunt op maatwerk. Zo'n persoonlijkheidsstructuur heeft autonomie nodig en verdraagt geen domesticering. Net zo min als het roofdier waarvan in de dierentuin nog maar een schaduw overblijft. Als ik het karakter van deze advocaat ietwat gechargeerd en generaliserend zou mogen typeren, dan denk ik aan dat van de 'jager's. In de biotoop van dit type advocaat ligt de nadruk op het individu, op zelfbeschikking en dat verdraagt slechts een losse organisatievorm; hij zoekt het werk op, volgt een experimentele aanpak, levert productgericht maatwerk en vertoont wispelturig gedrag. Maar als nu eens de inhoud van het werk verandert? Als de nadruk komt te liggen op een standaardaanpak, draaiboekregie en confectie en, vooral, op de organisatie? Dan is stellig een ander beroepsgedrag verkieslijk, waarschijnlijk zelfs nodig. Ik denk dan aan nogal wat transactiewerk, bijvoorbeeld M\&A practice en financial products.

Rechtskundige diensten die overigens niet zijn voorbehouden aan de advocaat. Zonder daarbij een kwalificering uit te spreken zou je bij dit type advocaat kunnen denken aan de 'landbouwer's. Die legt de nadruk op de collectiviteit en is bereid vanwege de grote aantallen een strakke(re) organisatie te accepteren, hij 'wacht op werk', richt zich op standaardisering van processen, levert cliëntgerichte confectie en vertoont voorspelbaar gedrag. Vanwege de aard van het werk is een hoge ratio partner/stagiaires en medewerkers mogelijk, en dat leidt tot een grote(re) winstgevendheid.

Professionalisering in de advocatuur vertoont wel enige gelijkenis met de ontwikkeling in de sport. Daar bestaan naast zeer verdienstelijke amateurs ook in toenemende mate profs, die ervoor hebben gekozen met alle moderne middelen 
en krachtig gesponsord de hoogste resultaten te behalen. Ook qua winstgevendheid. En daarmee is geruisloos het idealisme op de achtergrond geraakt. In de advocatuur zullen beide typen advocaten - jagers en landbouwers - ook naast elkaar bestaan. Zelfs zullen de karakteristieken verder worden geaccentueerd. En bij beide typen hoort een eigen markt en dienstverlening: de overwegend particuliere markt enerzijds en de zakelijke dienstverlening anderzijds. Daar dreigt meteen ook het gevaar voor het beroep. Want als die markten verder uit elkaar drijven en het verschil in winstgevendheid nog significanter wordt. zal de beroepsmatige aandacht voor de dienstverlening op financieel relatief minder interessante rechtsgebieden afkalven. Die keuze betekent onvermijdelijk dat het aanbod voor de particulieren zal opdrogen. Dat staat haaks op de maatschappelijke taak en functie van de balie. Niet alleen bedrijven en overheden moeten kunnen rekenen op deskundige rechtsbijstand door advocaten. Ook particulieren, misschien juist de consument, moet de effectieve toegang tot het recht en de rechter verzekerd weten door de rechtshulp van een toegewijd advocaat. De voortgaande professionalisering binnen ons beroep moet en mag niet tot gevolg hebben dat particulieren niet meer worden bediend. Dat hoeft ook niet, want professionalisering geeft immers mogelijkheden om ook deze consumentendiensten efficiënter en effectiever te gaan verrichten. Door bijvoorbeeld specialisering. automatisering en door toedeling op moeilijkheidsgraad. En hoewel altijd de particuliere markt qua winstgevendheid zal achterblijven bij de zakelijke markt zal het kantoren die zich richten op de commerciële dienstverlening niet misstaan om binnen hun muren de dienstverlening aan consumenten een plaats te geven. Vrijwilligheid is daarbij het parool. Maar wat als blijkt dat particulieren vergecfs aankloppen voor behoorlijke rechtshulp omdat (vrijwel) alle advocaten zich in deze booming economie hebben geworpen op de commerciële dienstverlening? Dan wordt het tijd om de balie indringender aan te spreken.

Desnoods met een verplichtstelling die gebaseerd zou kunnen worden op een percentage van de omzet te behalen in de particuliere markt. De advocatuur heeft uitbundig de smaak te pakken van het ondernemen, nu moet zij - net als het bedrijfsleven leren dat maatschappelijk verantwoord ondernemen nodig is om geaccepteerd te blijven worden in cen samenleving die de advocaat niet voor niets een bijzondere rol heeft toegekend. Daar mag diezelfde samenleving iets voor terugvragen. Zoals aandacht en inzet voor de burger die met de strafrechter in aanraking komt, of voor de burger die ruzie heeft met zijn werkgever of huisbaas, die werkloos is of zijn kinderen niet mag zien. Want professionalisering moet niet ontaarden in robotisering van ons beroep. Een beroep dat misschien nooit edel is geweest maar dat nog altijd kan worden.

\section{NOTEN}

1 Zie HR 18 december 1998, NJ 2000, 341 (van Olst/Ontvanger).

2 HR 14 juni 1985, NJ 1986, 175. Ook in de hoedanigheid van adviseur heeft hij geen verschoningsrecht (HR 6 mei 1986, NJ 1986, 813). Maar hij heeft een afgeleid verschoningsrecht als hij door een advocaat bij de verdediging wordt betrokken: HR 29 maart 1994, NJ 1994, 552 nt. 't H.

3 In samenhang hiermee bepaalt art. 27 dat degenen in de organen van de controlerende vennootschap die geen accountant zijn, geen zodanige bemoeienis met het controlewerk mogen hebben dat daardoor afbreuk wordt gedaan aan de controletaak.

4 Aldus Th.S. van IJsselmuiden in Kluwer Rechtspersonen, aantek. 3.7 op art. 393.

5 Ook David H. Maister bedient zich van de begrippen 'jager' en 'landbouwer' in 'Management van professionele organisaties', 1993, p. 361 en verder. 